\title{
Uncoupling protein-3 content is decreased in peripheral skeletal muscle of patients with COPD
}

\author{
H.R. Gosker*, P. Schrauwen", M.K.C. Hesselink", G. Schaart", G.J. van der Vusse ${ }^{+}$, E.F.M. Wouters*, \\ A.M.W.J. Schols*
}

Uncoupling protein-3 content is decreased in peripheral skeletal muscle of patients with COPD. H.R. Gosker, P. Schrauwen, M.K.C. Hesselink, G. Schaart, G.J. van der Vusse, E.F.M. Wouters, A.M.W.J. Schols. (C)ERS Journals Ltd 2003.

ABSTRACT: Mechanical efficiency is reduced in patients with chronic obstructive pulmonary disease (COPD). Furthermore, altered fibre-type distribution and metabolic profile has been observed in peripheral skeletal muscle of COPD patients. Since skeletal muscular uncoupling protein-3 (UCP3) has been implicated in the regulation of energy metabolism, the aim of this study was to assess UCP3 in peripheral skeletal muscle of COPD patients and healthy controls.

A total of 16 COPD patients and 11 healthy age-matched control subjects were studied. Mechanical efficiency was measured by means of cycle ergometry. Biopsies were taken from the vastus lateralis, and UCP3 and cytochrome $c$ (as a marker for mitochondrial content) levels were assessed by Western blotting. Muscle fibre types and metabolic profile were examined histochemically. UCP3 levels were markedly decreased in COPD compared to controls. In COPD patients, there was a positive correlation between UCP3 content and the forced expiratory volume in one second. UCP3 content was not related to mechanical efficiency, or other muscular data such as fibre types, markers of oxidative/glycolytic energy metabolism or cytochrome $c$.

The authors of this study conclude that uncoupling protein-3 content is decreased in peripheral skeletal muscle of patients with chronic obstructive pulmonary disease and is related to disease severity, but not to mechanical efficiency. The low uncoupling protein3 content is independent of the loss of oxidative capacity observed in these patients. Eur Respir J 2003; 22: 88-93.
Depts of *Pulmonology, ${ }^{*}$ Human Biology, and Movement Sciences, Nutrition Toxicology and Environment Research Institute Maastricht, and ${ }^{+}$Dept of Physiology, Cardiovascular Research Institute Maastricht, Maastricht University, Maastricht, the Netherlands.

Correspondence: H.R. Gosker, Maastricht University, PO Box 616, 6200 MD Maastricht, the Netherlands.

Fax: 31433875051

E-mail: H. Gosker@pul.unimaas.nl

Keywords: Chronic obstructive pulmonary disease, energy metabolism, muscle fibre types, peripheral skeletal muscle, uncoupling protein-3

Received: October 12002

Accepted after revision: February 242003

This study was supported by a grant from the Netherlands Asthma Foundation (project number 96.16). P. Schrauwen was supported by a grant from the Netherlands Organization for Scientific Research (NWO).
Total daily energy expenditure (EE) is often elevated in chronic obstructive pulmonary disease (COPD) patients [1], suggesting that these patients are characterised by hypermetabolism. Total daily EE consists of the resting EE, dietinduced thermogenesis and energy spent during daily activities. Although diet-induced thermogenesis is normal in COPD and can therefore be ignored [2], elevated resting EE has been observed in some COPD patients [3, 4]. However, it has been shown that total daily $\mathrm{EE}$ is elevated independent of resting EE [5], suggesting that the elevated total EE in COPD is related to daily activities. Due to the physical disabilities of patients with COPD, it must be assumed that these patients perform less physical activities compared to healthy subjects. Therefore, the elevated total daily EE is most likely explained by an elevated energy cost for physical activity. Indeed, mechanical efficiency, measured by means of submaximal exercise testing, is decreased in these patients [6].

The reason for the decreased mechanical efficiency in COPD patients is not known. SALA et al. [7] showed that for any specific workload, oxygen uptake of the leg is higher compared to healthy control subjects, suggesting that intrinsic muscular abnormalities are involved. Intrinsic abnormalities have indeed been found in peripheral skeletal muscles in COPD, of which, from a metabolic point of view, the most obvious are a reduction in the fibre type I proportion and a decreased oxidative capacity [8]. These findings suggest a potential relationship between mechanical inefficiency and muscular abnormalities in COPD. Recently, human homologues of the brown adipose tissue uncoupling protein 1 have been identified and these proteins are potentially important determinants of human energy metabolism [9, 10]. Uncoupling protein-3 (UCP3) is predominantly expressed in skeletal muscle and uncouples oxidative phosphorylation from adenosine trisphosphate (ATP) production [11]. The first evidence for a relation between UCP3 and energy metabolism came from genetic studies showing that the locus of the UCP3 gene is in the vicinity of markers strongly linked to resting EE [12]. Measurements of UCP3 messenger ribonucleic acid (mRNA) expression and protein content in relation to $\mathrm{EE}$ further supported a role for UCP3 in energy metabolism. In Pima Indians, SCHRAUWEN et al. [13] found a positive correlation between the mRNA expression of UCP3 and the sleeping metabolic rate. Decreased levels of UCP3 in humans accompany weight reduction and endurance training [14-16], conditions that result in a reduced resting metabolic rate and/or improved energy efficiency. Also, mice overexpressing UCP3 eat more but weigh less compared to wild-type controls, indicating an increased EE [17]. Finally, a clear inverse relationship was observed between mechanical efficiency and UCP3 expression in healthy subjects [14]. Although there is also evidence that the primary function of UCP3 is not the regulation of energy expenditure [11, 18, 19], the above-mentioned studies clearly indicate that UCP3 is related to human EE, perhaps as a secondary effect of its unknown function. Therefore, it is 
feasible that the increased EE and decreased mechanical efficiency in COPD could be attributed to elevated UCP3 levels. Elevated UCP3 levels in COPD would also be consistent with the finding that human UCP3 is highly expressed in type IIX (or IIB) fibres [20], since it has been shown that COPD patients have an increased proportion of type II fibres [8].

The aim of the present study was to investigate the UCP3 content of peripheral skeletal muscles of COPD patients, as compared to healthy age-matched controls. Furthermore, the relationship between UCP3 content, muscle fibre type distribution, muscle metabolic profile and mechanical efficiency of cycle ergometry was investigated.

\section{Methods}

A group of 15 patients with moderate-to-severe airflow obstruction and 11 healthy age-matched volunteers were studied. All patients had COPD, according to American Thoracic Society (ATS) guidelines [21], and chronic airflow limitation, defined as measured forced expiratory volume in one second (FEV1) $<70 \%$ of reference FEV1. In addition, all patients had a FEV1/forced vital capacity $(\mathrm{FVC})<70 \%$. Furthermore, patients had irreversible obstructive airway disease $(<10 \%$ improvement of FEV1 predicted baseline after $\beta_{2}$-agonist inhalation). Five of the 15 patients had severe COPD or disease severity stage III according to the ATS guidelines [21]. They were in a clinically stable condition and were not suffering from a respiratory tract infection or an exacerbation of their disease at least 4 weeks prior to the study. Exclusion criteria were malignancy, cardiac failure, distal arteriopathy, recent surgery, severe endocrine, hepatic or renal disorders, and use of anticoagulant medication. The healthy age-matched control subjects were volunteers recruited through an advertisement in a local newspaper. Written informed consent was obtained from all subjects and the study was approved by the medical ethical committee of the University Hospital Maastricht (Maastricht, the Netherlands).

\section{Pulmonary function tests}

All patients and control subjects underwent spirometry to determine, amongst others, FEV1 and FVC, with the highest value from at least three technically acceptable assessments being used. Residual volume and intrathoracic gas volume were assessed by whole-body plethysmography and diffusion capacity for carbon monoxide $(D \mathrm{~L}, \mathrm{CO})$ was measured by using the single-breath method (Masterlab; Jaeger, Wurzburg, Germany). All values obtained were related to a reference value and expressed as percentage of the predicted value [22]. Arterial oxygen tension $\left(\mathrm{Pa}, \mathrm{O}_{2}\right)$ was determined (ABL 330; Radiometer, Copenhagen, Denmark) in a blood sample obtained by puncture of the radial artery while breathing room air.

\section{Assessment of body composition}

Body height was determined to the nearest $0.5 \mathrm{~cm}$ with subjects standing barefoot, and body weight was assessed to the nearest $0.1 \mathrm{~kg}$ while subjects wore light clothing and no shoes. Whole-body fat-free mass (FFM), which consists of lean mass and bone mineral mass, was determined by scanning each subject on a DPX bone densitometer (Lunar Radiation Corporation, Madison, WI, USA) as described previously [23]. Weight parameters were divided by squared body height $\left(\mathrm{kg} \cdot \mathrm{m}^{-2}\right)$, resulting in the body mass index (BMI) and FFM index (FFMI), to adjust for body surface [24].

\section{Resting energy expenditure}

Energy expenditure at rest (REE) was measured by indirect calorimetry using a ventilated hood system (Oxycon Beta $\mathbb{R}$; Jaeger). The reproducibility and validity of this method in COPD patients was shown by ScHOLS et al. [25]. The system was calibrated daily at the start of the experiment. The accuracy of the system was regularly assessed using a methanol combustion test. Measurements were performed in the early morning after an overnight fast, while the subject was comfortably lying on a bed in supine position. EE was calculated from oxygen consumption and carbon dioxide production using the abbreviated Weir formula [26]. Measured REE was expressed as percentage of predicted REE, which was calculated using the linear regression equation of REE on FFM, as described by CReutzberg et al. [4].

\section{Mechanical efficiency during cycle ergometry}

Recently, a close correlation between mechanical efficiency during submaximal exercise testing and the ratio of peak oxygen consumption ( $\mathrm{VO}_{2}$,peak) to peak work rate (WRpeak) during maximal exercise testing was found in COPD [27]. Therefore, in this study the $V \mathrm{O}_{2}$,peak/WRpeak was used as a measure of gross efficiency in the current study. All subjects performed an incremental exercise test on an electrically braked cycle ergometer (Corival $400 \AA$; Lode, Groningen, the Netherlands) under the supervision of a chest physician. Before the start of the test, while seated on the cycle ergometer, ventilation characteristics at rest were analysed for $2 \mathrm{~min}$. During the entire exercise test, expired gases were investigated using breath-by-breath analysis through a breath-

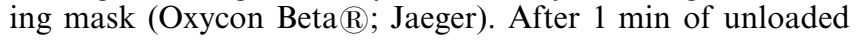
cycling, power was increased by $10 \mathrm{~W}$ every min for patients. For the control subjects, the load was increased by $15-25 \mathrm{~W}$ every $1 \mathrm{~min}$, so that the length of the exercise test was comparable for patients and controls. None of the subjects knew the exercise load and all were encouraged to cycle at 60 revs $\cdot \min ^{-1}$ until exhaustion. $V \mathrm{O}_{2}$,peak and WRpeak were measured at the moment of cessation of the exercise. A high $V \mathrm{O}_{2}$,peak-to-WRpeak ratio corresponds to a low gross efficiency.

\section{Collection and processing of muscle tissue}

Postabsorptive muscle biopsies of the lateral part of the quadriceps femoris were obtained under local anesthesia using the needle biopsy technique [28]. Part of the tissue was used to obtain serial cryostat cross-sections $(10 \mu \mathrm{m})$ for histochemistry. Evaluation of fibre type distribution was performed using a combination of myofibrillar ATPase (mATPase) staining and immunohistochemistry, as described previously [29]. In short, the mATPase acidic and alkaline pre-incubations were performed at $\mathrm{pH} 4.4$ and $\mathrm{pH} 10.4$, respectively. Double pre-incubation was performed at $\mathrm{pH} 10.4$ and $\mathrm{pH}$ 4.6. After pre-incubation, sections were stained and mounted. Immunohistochemistry was performed with a panel of monoclonal anitibodies (mAb), respectively, anti-type I myosin heavy chain (MyHC) (mAb 219-1D1), anti-type IIA MyHC (mAb 333-7H1) and antitypes IIA+IIX MyHC (mAb 332-3D4). Fibre cross-sectional area (CSA) was measured with an interactive image analysis system (Leica QWin Image Analysis System; Leica Microsystems 
BV, Rijswijk, the Netherlands), as reported previously [30]. The relative contribution of type II fibres to total fibre CSA (\%CSA of type II fibres) was calculated. Metabolic profile of muscle fibres was evaluated by staining for cytochrome $c$ oxidase (COX) and succinate dehydrogenase (SDH) activity, as markers for oxidative energy metabolism, and glycogen phosphorylase (GlyP) activity, for glycolytic energy metabolism, as described previously [29]. In short, for COX activity, staining sections were incubated for $1 \mathrm{~h}$ in a $50 \mathrm{mM}$ Tris/ $\mathrm{HCl}$

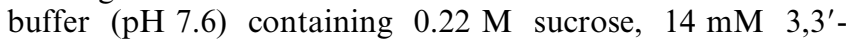
diaminobenzidine tetrahydrochloride, $80 \mu \mathrm{M}$ cytochrome $c$ and $1300 \mathrm{U}$ catalase. SDH activity staining was performed by incubating sections for $1 \mathrm{~h}$ at $37^{\circ} \mathrm{C}$ in a $0.2 \mathrm{M}$ sodium phosphate buffer containing $0.1 \mathrm{M}$ succinic acid and $1.2 \mathrm{mM}$ nitro blue tetrazolium. GlyP staining was performed by incubating sections for $5 \mathrm{~min}$ in a $43 \mathrm{mM}$ sodium acetate buffer ( $\mathrm{pH}$ 5.6) containing $7 \mathrm{mM}$ glucose-1-phosphate, $1 \mathrm{mM}$ adenosine monophosphate, $0.01 \%$ glycogen and $15 \%$ ethanol, after which the newly formed polysaccharide was coloured with Lugol's iodine. Three staining intensities were determined, reflecting fibre enzyme activity: positive $(+)$, negative $(-)$ or intermediate $( \pm)$. The current authors have previously reported altered fibre type distribution, fibre CSAs and metabolic profiles as presented in the current study [29, 30]. The remaining parts of the muscle biopsies were homogenised in ice-cold Tris-ethylenediaminetetraacetic acid buffer at $\mathrm{pH} 7.4$ and then the homogenates were sonicated for $4 \times 15 \mathrm{~s}$. Subsequently, two volumes of each skeletal muscle homogenate and one volume of sodium dodecylsulphate (SDS) sample buffer were boiled for $4 \mathrm{~min}$. Next, 13\% polyacrylamide gels containing $0.1 \%$ SDS were loaded with equal amounts of protein from each sample and electrophoresis was performed using a Mini-Protean 3 Electrophoresis Cell (Bio-Rad Laboratories, Hercules, CA, USA). After gel electrophoresis, this gel was scanned, and the optical density of the 43-kDa band, previously immuno-identified to represent actin, was assessed. Then, a second gel was prepared and loaded with the sample volume (which had been recalculated based on the optical density of the actin band), after which Western blotting was performed using a Mini Trans-Blot Electrophoretic Transfer Cell (Bio-Rad Laboratories), as described previously [20]. A rabbit polyclonal UCP3 antibody (code 1331; kindly provided by L.J. Slieker, Eli Lilly, Indianapolis, IN, USA) was prepared against a 20-amino acid (aa) peptide (human sequence aa 147-166), which recognises both the long and the short form of UCP3 and was previously shown to not recognise UCP2. The antibody was affinity-purified on a Sulfolink column (Pierce; Omnilabo International, Breda, the Netherlands) containing the peptide coupled through a $\mathrm{COOH}$-terminal cysteine. Cross-reaction of the antibody with other proteins was checked by examining the entire 5- to $94-\mathrm{kDa}$ range for additional bands. For a more detailed description of the selectivity and specificity checks see previous reports $[15,20,31]$. The cytochrome $c$ level, as a marker of mitochondrial content, was measured comparably, using a mouse monoclonal cytochrome $c$ antibody (BD PharMingen, Woerden, the Netherlands). Both UCP3 and cytochrome $c$ were expressed as arbitrary units (AU).

\section{Statistical analysis}

Data were analysed using the unpaired Student's t-test (corrected for unequal variances if appropriate), one-way analysis of variance (with unpaired Student's t-test as post-hoc test) or the Pearson correlation test, as appropriate [32]. Data
Table 1.-Subject characteristics for controls and patients with chronic obstructive pulmonary disease

\begin{tabular}{|c|c|c|}
\hline & Controls & COPD \\
\hline Subjects $\mathrm{n}$ & 11 & 15 \\
\hline Sex F:M & $1: 10$ & $3: 12$ \\
\hline Age yrs & $64 \pm 1$ & $67 \pm 2$ \\
\hline $\mathrm{BMI} \mathrm{kg} \cdot \mathrm{m}^{-2}$ & $26.1 \pm 1$ & $23.9 \pm 1$ \\
\hline FFMI $\mathrm{kg} \cdot \mathrm{m}^{-2}$ & $19.5 \pm 0.6$ & $17.2 \pm 0.5 * *$ \\
\hline FEV1 \% pred & $105 \pm 5$ & $42 \pm 4 * * *$ \\
\hline FVC $\%$ pred & $115 \pm 4.0$ & $83 \pm 3.8^{* * *}$ \\
\hline $\mathrm{Pa}, \mathrm{O}_{2} \mathrm{kPa}$ & $11.4 \pm 0.5$ & $9.9 \pm 0.3^{*}$ \\
\hline$D$ L,CO $\%$ pred & $118 \pm 7$ & $63 \pm 7 * * *$ \\
\hline RV \% pred & $114 \pm 5$ & $167 \pm 8 * * *$ \\
\hline ITGV $\%$ pred & $107 \pm 5$ & $144 \pm 6 * * *$ \\
\hline Plasma glucose $\mathrm{mmol} \cdot \mathrm{L}^{-1}$ & $6 \pm 0.8$ & $5.6 \pm 0.9$ \\
\hline REE kcal $\cdot 24 \mathrm{~h}^{-1} \cdot \mathrm{kg} \mathrm{FFM}^{-1}$ & & $27.3 \pm 1.2$ \\
\hline \multicolumn{3}{|l|}{ Muscle biopsy data } \\
\hline Cytochrome $c$ AU & $141 \pm 20$ & $60 \pm 8 * *$ \\
\hline Type I fibres \% & $40 \pm 4$ & $19 \pm 4 * * *$ \\
\hline Type IIA fibres \% & $30 \pm 4$ & $35 \pm 3$ \\
\hline Type IIX fibres \% & $30 \pm 4$ & $46 \pm 5^{*}$ \\
\hline Type II \% CSA \% & $62 \pm 5$ & $74 \pm 4$ \\
\hline $\mathrm{COX}+$ fibres $\%$ & $47 \pm 4$ & $20 \pm 3 * * *$ \\
\hline $\mathrm{SDH}+$ fibres $\%$ & $38 \pm 4$ & $14 \pm 3 * * *$ \\
\hline GlyP+ fibres \% & $38 \pm 5$ & $38 \pm 4$ \\
\hline
\end{tabular}

Data are presented as mean \pm SEM. F: female; M: male; BMI: body mass index; FFMI: fat-free mass index; FEV1: forced expiratory volume in one second; FVC: forced vital capacity; $\mathrm{Pa}, \mathrm{O}_{2}$ : arterial oxygen tension; $D \mathrm{~L}, \mathrm{CO}$ : diffusion capacity for carbon monoxide; $\mathrm{RV}$ : residual volume; ITGV: intrathoracic gas volume; REE: resting energy expenditure; AU: arbitrary units; type II \% CSA: relative contribution of type II fibres to total fibre cross-sectional area; $\mathrm{COX}+, \mathrm{SDH}+$ and GlyP+: fibres staining positive for cytochrome $c$ oxidase, succinate dehydrogenase and glycogen phosphorylase, respectively. *: $\mathrm{p}<0.05 ; * *$ : $\mathrm{p}<0.01 ; * * * \mathrm{p}<0.001$, as compared to controls.

are represented as the mean \pm SEM. A two-tailed probability value of $<0.05$ was considered statistically significant.

\section{Results}

The characteristics of patients and control subjects are summarised in table 1 . There were no differences in sex or age between the groups. FFMI was significantly lower in COPD while BMI was not significantly different from controls. Plasma glucose levels were within normal range in COPD. The proportions of type I fibres and fibres with high oxidative capacity were markedly lower in patients, whereas the fibre type IIX proportion was higher compared to healthy subjects. The relative contribution of the CSA of type II fibres tended to be larger in COPD, but this was not statistically significant $(\mathrm{p}=0.085)$.

Figure 1 shows a representative Western blot of four controls and four COPD patients. On average, UCP3 content was $50 \%$ lower in COPD patients compared with control subjects ( $95 \pm 13$ versus $47 \pm 8$ AU; $\mathrm{p}=0.004$ ), as shown in figure 2 . There was a significant positive correlation between the FEV1 and the peripheral skeletal muscle UCP3 content in COPD patients $(\mathrm{r}=0.66, \mathrm{p}<0.01)$, as shown in figure 3 . There was no correlation between resting energy expenditure and UCP3 content in COPD. Five of the 15 patients had severe COPD or disease severity stage III, according to the ATS guidelines. These patients had a markedly lower UCP3 content compared to the patients with moderate COPD (19 \pm 4.4 versus $61 \pm 8.9 \mathrm{AU} ; \mathrm{p}=0.001)$. The $V \mathrm{O}_{2}$, peak/WRpeak was significantly higher in COPD than in controls $(16.7 \pm 1.2$ versus $\left.10.2 \pm 0.3 \mathrm{~mL} \cdot \mathrm{min}^{-1} \cdot \mathrm{watt}^{-1} ; \mathrm{p}<0.001\right)$. In addition, $V \mathrm{O}_{2}$, peak/ 


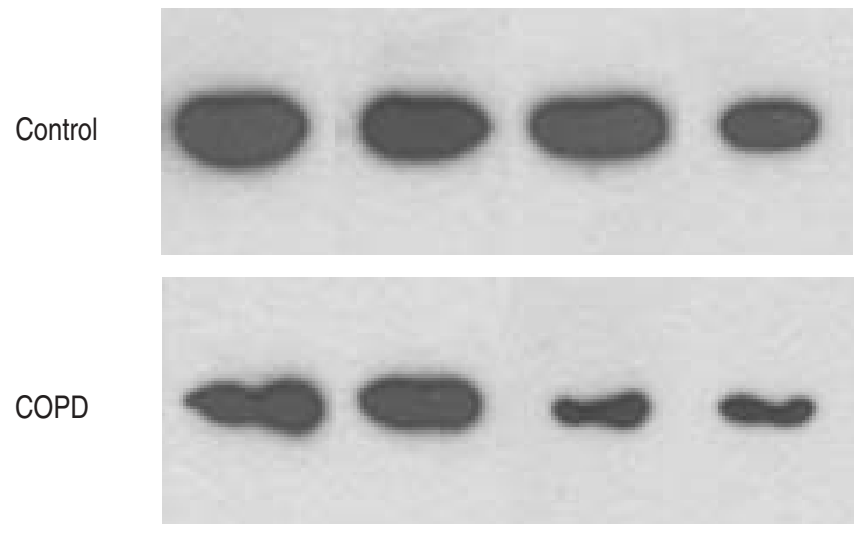

Fig. 1. - Representative sample of uncoupling protein-3 (UCP3) using the Western blot technique. Equal amounts of protein (normalised on the band identified as actin) were loaded in every lane. Blotting and antibody incubation were performed simultaneously for control and chronic obstructive pulmonary disease (COPD) samples, and all samples were exposed to the same film. UCP3 was identified as the $33 \mathrm{kDa}$ band.

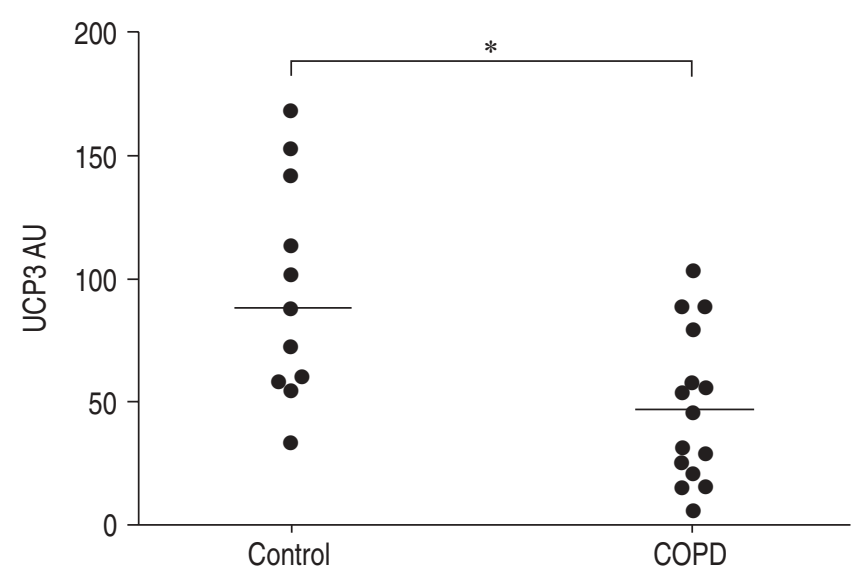

Fig. 2. - Peripheral skeletal muscle uncoupling protein-3 (UCP3) content in chronic obstructive pulmonary disease (COPD) patients $(\mathrm{n}=15)$ and healthy controls $(\mathrm{n}=11)$. Horizontal bars indicate median values. AU: arbitrary units. *: $\mathrm{p}<0.01$ between groups.

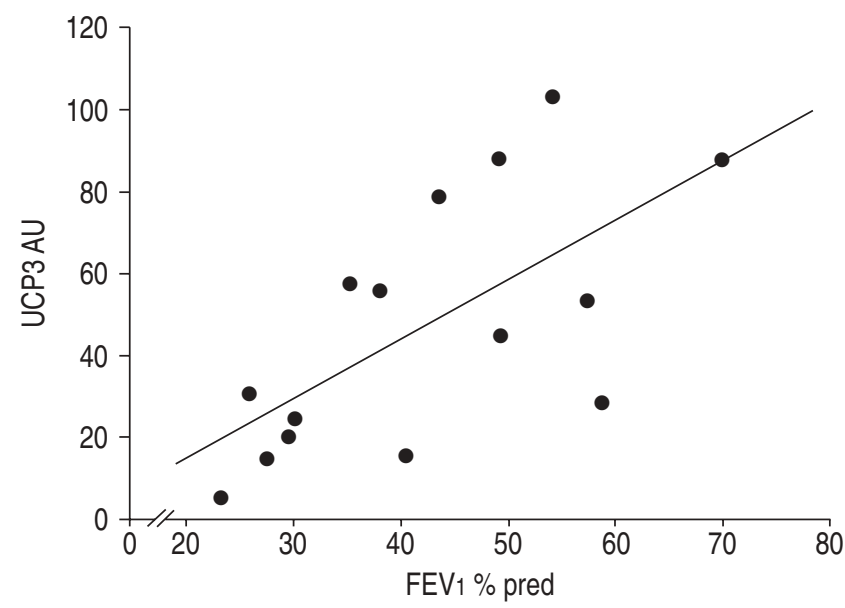

Fig. 3.-Correlation between the forced expiratory volume in one second (FEV1) and peripheral skeletal muscle uncoupling protein-3 (UCP3) content in chronic obstructive pulmonary disease patients $(\mathrm{r}=0.66, \mathrm{p}<0.01)$.

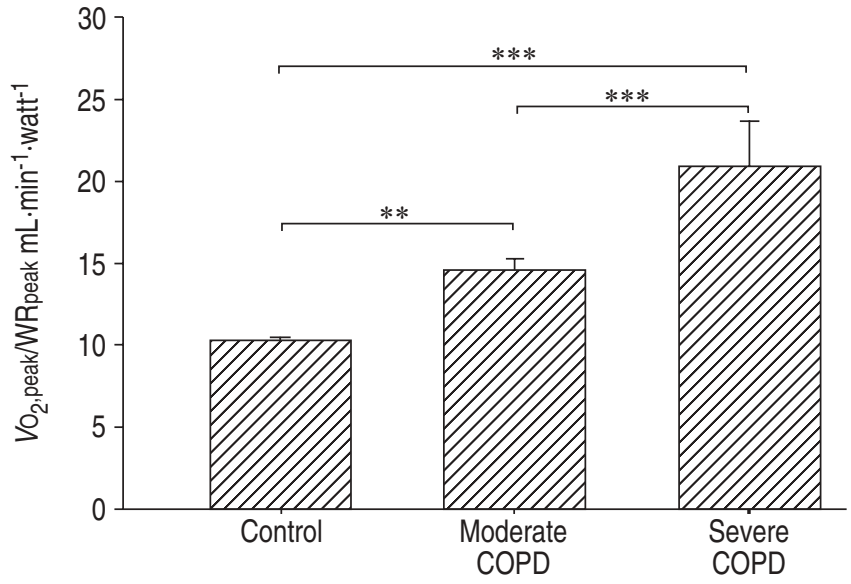

Fig. 4. - Mechanical efficiency of leg exercise in patients with moderate or severe obstructive pulmonary disease (COPD) and healthy controls. Error bars indicate the SEM. ${ }^{* *}: \mathrm{p}<0.01$; ${ }^{* * *}$ : $\mathrm{p}<0.001$, as compared to controls.

WRpeak was significantly higher in patients with severe COPD than in patients with moderate COPD (fig. 4). In COPD, an inverse correlation was found between the $V \mathrm{O}_{2}$,peak/WRpeak and UCP3 content $(\mathrm{r}=-0.568 ; \mathrm{p}=0.027)$, but after adjustment for the disease severity, as measured by the FEV1, this correlation was not statistically significant $(\mathrm{r}=-0.402 ; \mathrm{p}=0.154)$. There was no relationship between $\mathrm{VO}_{2}$, peak/WRpeak and fibre types or indices of metabolic profile.

To assess whether the reduced UCP3 content could be explained by the reduced oxidative capacity, cytochrome $c$ content was measured in the same samples. There was no significant correlation $(\mathrm{r}=0.43$; $\mathrm{p}=0.13)$ between $\mathrm{UCP} 3$ content and cytochrome $c$ content in COPD. In addition, in the patient group, there were no correlations between UCP3 and the proportions of fibres with high staining activities for cytochrome $c$ oxidase, succinate dehydrogenase or glycogen phosphorylase. Furthermore, there was no relationship between UCP3 and fibre type distribution in COPD, nor did the UCP3 content correlate with the relative contribution of type II fibres to the total fibre CSA (or \% CSA of type II fibres). Peripheral skeletal muscle UCP3 content also did not correlate with fat-free mass (a measure of muscle mass). DL,CO did not correlate with UCP3 content in patients. There was a correlation between UCP3 and $\mathrm{Pa}, \mathrm{O}_{2}$, but not after adjustment for FEV1.

\section{Discussion}

The main finding of the present study is the significantly lower UCP3 content in peripheral skeletal muscle of COPD patients, being lowest in the patients with the highest severity of COPD. This is the opposite of what the authors had expected with respect to mechanical inefficiency and the increased muscle fibre type II proportion in COPD. The low UCP3 levels could not be quantitatively attributed to the reduction in muscle mass or other muscular abnormalities, since UCP3 levels did not correlate with the fat-free mass index, nor with fibre type distribution or muscle fibre metabolic profile.

The data presented here clearly indicate that decreased leg efficiency in COPD is not the result of elevated muscular UCP3 contents. First of all, reduced instead of elevated levels of UCP3 were found. In addition, the expected inverse correlation between leg efficiency and UCP3 was not found. This result is in contrast to findings observed in healthy 
subjects, in which low levels of muscular UCP3 contents were associated with increased mechanical efficiency [14], although UCP3 was not evaluated in subjects with such a low mechanical efficiency as in the current COPD group. It can be speculated that the reduced UCP3 levels in COPD represent a compensatory adaptation to the decreased mechanical efficiency and/or elevated EE in these patients. However, there is also growing evidence that the primary function of UCP3 is not the regulation of energy metabolism, although UCP3 might (as a secondary effect of its primary function) influence energy metabolism in certain circumstances. For example, fasting, a condition associated with energy conservation, results in upregulation of UCP3 [18]. Also, UCP3 knockout mice have normal $\mathrm{EE}$ and body weight, even though their mitochondria show improved coupling [33]. Thus, the primary function of UCP3 is at yet unknown. UCP3 has been suggested to be involved in the regulation of fuel metabolism. In this context, it is interesting to note the accumulating evidence that substrate metabolism is also impaired in COPD patients. Although no abnormal plasma glucose levels were found in COPD in the current study, the current authors have previously reported the presence of hyperinsulinaemia in moderate-to-severe COPD patients [34]. Impaired glucose tolerance and impaired $\beta$-adrenoceptor-mediated lipolysis have been shown for COPD [35, 36]. Furthermore, reduced activities of enzymes involved in oxidative substrate metabolism have been found in the vastus lateralis of COPD patients [8]. With respect to these abnormalities it is feasible that the reduced UCP3 contents in COPD may be associated with impaired substrate metabolism [37, 38]. Mice overexpressing UCP3 show improved glucose metabolism (reduced fasting plasma glucose and insulin levels, and improved glucose tolerance after an oral glucose load), which suggests a role for UCP3 in carbohydrate metabolism and type II diabetes [17]. Indeed, SCHRAUWEN et al. [39] recently reported markedly reduced levels of UCP3 in patients with type II diabetes compared to control subjects. If and how UCP3 is involved in substrate metabolism in COPD needs to be further exploited. Alternatively, UCP3 has been suggested to be involved in mitochondrial fatty acid handling [40, 41]. $\beta$-Hydroxyacyl coenzyme A dehydrogenase, an enzyme involved in the $\beta$-oxidation of fatty acids, was shown to be reduced in COPD [42] and it is tempting to speculate that COPD patients are characterised by impairments in fatty acid metabolism. However, further studies are needed to characterise substrate metabolism in COPD in more detail and to reveal the exact function of UCP3 in substrate metabolism in this group of patients. Another putative function of UCP3 is the regulation of reactive oxygen species production [43]. Several observations point towards an imbalance between the production of oxygen species and the antioxidant status in muscles of COPD patients [44-46]. Whether reduced UCP3 is involved in, or associated with, the defence against reactive oxygen species in COPD needs further examination.

The finding of lower UCP3 levels in COPD is also remarkable considering that human UCP3 is predominantly expressed in type II fibres [20]. Despite an increase in the fibre type II proportion in COPD patients in the current study, there was a decrease of the UCP3 levels. The observed increase in the fibre type II proportion is, however, accompanied by selective atrophy of type II fibres in COPD, as reported recently [30]. The relative contribution of type II fibres to the total fibre CSA is not larger in the patient group and this may partly explain why peripheral muscular UCP3 content is not increased in COPD. Alternatively, since oxidative capacity is also reduced in these patients and UCP3 is a mitochondrial protein, a reduction of UCP3 could be explained by a reduction in the mitochondrial content. However, no correlation was found between UCP3 and cytochrome $c$ as a marker of mitochondrial content. There were also no relationships between UCP3 and the proportions of fibres staining positive for the mitochondrial enzymes COX or SDH. It can therefore be concluded from the present data that the low UCP3 content in COPD is probably not just an epiphenomena of altered muscle fibre composition and related oxidative capacity. Further studies are needed to examine whether the reduction of UCP3 in COPD is fibre type specific.

In conclusion, to the best of the current authors' knowledge, this is the first time that uncoupling protein-3 content in the peripheral skeletal muscle of patients with chronic obstructive pulmonary disease has been studied. In contrast to what was expected, uncoupling protein-3 levels in patients were substantially lower compared to healthy control subjects. In addition, it can be concluded that uncoupling protein-3 is not responsible for the decreased mechanical efficiency and, therefore, is probably not involved in elevated energy expenditure in these patients. The clinical significance of the reduced uncoupling protein- 3 in chronic obstructive pulmonary disease and its relation to disease severity requires further investigation.

Acknowledgements. The authors would like to thank L.J. Slieker from Eli Lilly for providing the UCP3 antibody and A.F.M. Moorman for providing the antibodies against MyHC isoforms I, IIA and IIA+IIX.

\section{References}

1. Baarends EM, Schols AM, Pannemans DL, Westerterp KR, Wouters EF. Total free living energy expenditure in patients with severe chronic obstructive pulmonary disease. $A m \mathrm{~J}$ Respir Crit Care Med 1997; 155: 549-554.

2. Hugli O, Frascarolo P, Schutz Y, Jequier E, Leuenberger P, Fitting JW. Diet-induced thermogenesis in chronic obstructive pulmonary disease. Am Rev Respir Dis 1993; 148: 14791483 .

3. Schols AMWJ, Fredrix EW, Soeters PB, Westerterp KR, Wouters EF. Resting energy expenditure in patients with chronic obstructive pulmonary disease. Am J Clin Nutr 1991; 54: 983-987.

4. Creutzberg EC, Schols AMWJ, Bothmer-Quaedvlieg FCM, Wouters EFM. Prevalence of an elevated resting energy expenditure in patients with chronic obstructive pulmonary disease in relation to body composition and lung function. Eur J Clin Nutr 1998; 52: 396-401.

5. Baarends EM, Schols AM, Westerterp KR, Wouters EF. Total daily energy expenditure relative to resting energy expenditure in clinically stable patients with COPD. Thorax 1997; 52: 780-785.

6. Baarends EM, Schols AM, Akkermans MA, Wouters EF. Decreased mechanical efficiency in clinically stable patients with COPD. Thorax 1997; 52: 981-986.

7. Sala E, Roca J, Marrades RM, et al. Effects of endurance training on skeletal muscle bioenergetics in chronic obstructive pulmonary disease. Am J Respir Crit Care Med 1999; 159: $1726-1734$

8. Gosker HR, Wouters EF, van der Vusse GJ, Schols AM Skeletal muscle dysfunction in chronic obstructive pulmonary disease and chronic heart failure: underlying mechanisms and therapy perspectives. Am J Clin Nutr 2000; 71: 10331047.

9. Ricquier D, Bouillaud F. The uncoupling protein homologues: UCP1, UCP2, UCP3, StUCP and AtUCP. Biochem J 2000; 345: 161-179.

10. Schrauwen P, Walder K, Ravussin E. Human uncoupling proteins and obesity. Obes Res 1999; 7: 97-105.

11. Boss O, Samec S, Paoloni-Giacobino A, et al. Uncoupling 
protein-3: a new member of the mitochondrial carrier family with tissue-specific expression. FEBS Lett 1997; 408: 39-42.

12. Bouchard C, Perusse L, Chagnon YC, Warden C, Ricquier D. Linkage between markers in the vicinity of the uncoupling protein 2 gene and resting metabolic rate in humans. Hum Mol Genet 1997; 6: 1887-1889.

13. Schrauwen P, Xia J, Bogardus C, Pratley RE, Ravussin E. Skeletal muscle uncoupling protein 3 expression is a determinant of energy expenditure in Pima Indians. Diabetes 1999; 48: 146-149.

14. Schrauwen P, Troost FJ, Xia J, Ravussin E, Saris WH. Skeletal muscle UCP2 and UCP3 expression in trained and untrained male subjects. Int J Obes Relat Metab Disord 1999; 23: 966-972.

15. Schrauwen $\mathrm{P}$, Schaart G, Saris WH, et al. The effect of weight reduction on skeletal muscle UCP2 and UCP3 mRNA expression and UCP3 protein content in type II diabetic subjects. Diabetologia 2000; 43: 1408-1416.

16. Vidal-Puig A, Rosenbaum M, Considine RC, et al. Effects of obesity and stable weight reduction on UCP2 and UCP3 gene expression in humans. Obes Res 1999; 7: 133-140.

17. Clapham JC, Arch JR, Chapman H, et al. Mice overexpressing human uncoupling protein-3 in skeletal muscle are hyperphagic and lean. Nature 2000; 406: 415-418.

18. Millet L, Vidal H, Andreelli F, et al. Increased uncoupling protein-2 and -3 mRNA expression during fasting in obese and lean humans. J Clin Invest 1997; 100: 2665-2670.

19. Gong DW, Monemdjou S, Gavrilova O, et al. Lack of obesity and normal response to fasting and thyroid hormone in mice lacking uncoupling protein-3. J Biol Chem 2000; 275: 16251-16257.

20. Hesselink MK, Keizer HA, Borghouts LB, et al. Protein expression of UCP3 differs between human type 1, type 2a, and type 2b fibers. FASEB J 2001; 15: 1071-1073.

21. ATS. Standards for the diagnosis and care of patients with chronic obstructive pulmonary disease. Am J Respir Crit Care Med 1995; 152: S77-S121.

22. Quanjer P, Tammeling GJ, Cotes JE, Pedersen OF, Peslin R, Yernault JC. Standardized lung function testing. Eur Respir $J$ 1993; 6: 5-40.

23. Engelen MPKJ, Schols AMWJ, Heidendal GAK, Wouters EFM. Dual-energy X-ray absorptiometry in the clinical evaluation of body composition and bone mineral density in patients with chronic obstructive pulmonary disease. Am J Clin Nutr 1998; 68: 1298-1303.

24. VanItallie TB, Yang MU, Heymsfield SB, Funk RC, Boileau RA. Height-normalized indices of the body's fat-free mass and fat mass: potentially useful indicators of nutritional status. Am J Clin Nutr 1990; 52: 953-959.

25. Schols AM, Schoffelen PF, Ceulemans H, Wouters EF, Saris WH. Measurement of resting energy expenditure in patients with chronic obstructive pulmonary disease in a clinical setting. JPEN J Parenter Enteral Nutr 1992; 16: 364-368.

26. Weir JB. New methods for calculating metabolic rate with special reference to protein metabolism. 1949. Nutrition 1990; 6: 213-221.

27. Franssen FME, Wouters EFM, Baarends EM, Akkermans MA, Schols AMWJ. Arm mechanical efficiency and arm exercise capacity are relatively preserved in chronic obstructive pulmonary disease. Med Sci Sports Exerc 2002; 34: 1570-1576.

28. Bergstrom L. Muscle electrolytes in man. Determination by neutron activation analysis on needle biopsy specimens. A study on normal subjects, kidney patients, and patients with chronic diarrhea. Scand J Clin Lab Invest 1962; 68: 1-110.

29. Gosker HR, van Mameren H, van Dijk PJ, et al. Skeletal muscle fibre type shifting and metabolic profile in patients with COPD. Eur Respir J 2002; 19: 617-626.
30. Gosker HR, Engelen MPKJ, van Mameren H, et al. Muscle fiber type IIX atrophy is involved in the loss of fat-free mass in chronic obstructive pulmonary disease. Am J Clin Nutr 2002; 76: 113-119.

31. Hesselink MK, Greenhaff PL, Constantin-Teodosiu D, et al. Increased uncoupling protein 3 content does not affect mitochondrial function in human skeletal muscle in vivo. $J$ Clin Invest 2003; 111: 479-486.

32. Altman DG, Gore SM, Gardner MJ, Pocock SJ. Statistical guidelines for contributors to medical journals. $\mathrm{Br} \mathrm{Med} J \mathrm{Clin}$ Res Ed 1983; 286: 1489-1493.

33. Vidal-Puig AJ, Grujic D, Zhang CY, et al. Energy metabolism in uncoupling protein 3 gene knockout mice. $J$ Biol Chem 2000; 275: 16258-16266.

34. Engelen MP, Wouters EF, Deutz NE, Menheere PP, Schols AM. Factors contributing to alterations in skeletal muscle and plasma amino acid profiles in patients with chronic obstructive pulmonary disease. Am J Clin Nutr 2000; 72: $1480-1487$.

35. Hjalmarsen A, Aasebo U, Birkeland K, Sager G, Jorde R. Impaired glucose tolerance in patients with chronic hypoxic pulmonary disease. Diabetes Metab 1996; 22: 37-42.

36. Schiffelers SL, Blaak EE, Baarends EM, et al. $\beta$-Adrenoceptormediated thermogenesis and lipolysis in patients with chronic obstructive pulmonary disease. Am J Physiol Endocrinol Metab 2001; 280: E357-E364.

37. Samec S, Seydoux J, Dulloo AG. Role of UCP homologues in skeletal muscles and brown adipose tissue: mediators of thermogenesis or regulators of lipids as fuel substrate? FASEB J 1998; 12: 715-724.

38. Garcia-Martinez C, Sibille B, Solanes G, et al. Overexpression of UCP3 in cultured human muscle lowers mitochondrial membrane potential, raises ATP/ADP ratio, and favors fatty acid versus glucose oxidation. FASEB J 2001; 15: 20332035.

39. Schrauwen P, Hesselink MK, Blaak EE, et al. Uncoupling protein 3 content is decreased in skeletal muscle of patients with type 2 diabetes. Diabetes 2001; 50: 2870-2873.

40. Himms-Hagen J, Harper ME. Physiological role of UCP3 may be export of fatty acids from mitochondria when fatty acid oxidation predominates: an hypothesis. Exp Biol Med (Maywood) 2001; 226: 78-84.

41. Schrauwen P, Saris WH, Hesselink MK. An alternative function for human uncoupling protein 3: protection of mitochondria against accumulation of nonesterified fatty acids inside the mitochondrial matrix. FASEB $J$ 2001; 15: 2497-2502.

42. Maltais F, Simard AA, Simard C, Jobin J, Desgagnes P, LeBlanc P. Oxidative capacity of the skeletal muscle and lactic acid kinetics during exercise in normal subjects and in patients with COPD. Am J Respir Crit Care Med 1996; 153: 288-293.

43. Pecqueur C, Couplan E, Bouillaud F, Ricquier D. Genetic and physiological analysis of the role of uncoupling proteins in human energy homeostasis. $J$ Mol Med 2001; 79: 48-56.

44. Pouw EM, Schols AMWJ, Vusse van der GJ, Wouters EFM Elevated inosine monophosphate levels in resting muscle of patients with stable COPD. Am J Respir Crit Care Med 1998; 157: 453-457.

45. Rahman I, Morrison D, Donaldson K, MacNee W. Systemic oxidative stress in asthma, COPD, and smokers. Am J Respir Crit Care Med 1996; 154: 1055-1060.

46. Engelen MP, Schols AM, Does JD, Deutz NE, Wouters EF Altered glutamate metabolism is associated with reduced muscle glutathione levels in patients with emphysema. $\mathrm{Am} \mathrm{J}$ Respir Crit Care Med 2000; 161: 98-103. 